\title{
RACISMO ACADÊMICO E SEUS AFETOS ${ }^{1}$
}

\author{
Academic racism and its affections
}

\author{
Mariléa de Almeida ${ }^{2}$
}

\begin{abstract}
RESUMO
Neste artigo, o racismo acadêmico é compreendido como uma tecnologia de poder cujas práticas de discriminação racial acontecem de forma velada ou explícita em instituições acadêmicas. Partindo de uma experiência pessoal, o texto pergunta de que modo os circuitos afetivos e as relações de poder sustentam o silêncio e o manejo dos incômodos em torno dessas práticas. O trabalho fundamenta-se teoricamente nas abordagens sobre racismo, afeto e relações de poder, inspiradas nas análises de Achile Mbembe (2014), Beatriz Nascimento (2018), Frantz Fanon (2008) e Maria Aparecida da Silva Bento (2014).
\end{abstract}

Palavras-chave: racismo acadêmico, afeto, relações de poder.

\begin{abstract}
In this article, academic racism is understood as a technology whose practices of racial discrimination take place in a veiled or explicit manner in academic institutions. Starting from a personal experience, the text asks how affective circuits and power relationships sustain silence and handling of discomforts surrounding the practices of academic racism. The work is theoretically based on an analysis of the racism, affection,
\end{abstract}

\footnotetext{
1 Uma versão desse texto foi apresentada no Seminário Ascensão e Queda do Paraíso Tropical, dia 27/10, no Centro de Formação do SESC/ SP. Agradeço às leituras e sugestões de Márcia Cristina Rogério de Almeida e Terra Johari.

2 Doutora em História IFCH/ UNICAMP. (2018). Em 2015, realizou o doutorado sanduíche na Columbia University (Nova York), com foco nos feminismos negros estadunidenses. Mestre em História pela Universidade Severino Sombra. Especialista (Pós-graduação lato sensu) em Filosofia pelo Centro Universitário de Barra Mansa. Especialista (Pós-graduação lato Sensu) em História do Brasil Pós Trinta pela Universidade Federal Fluminense. Foi professora de história nos segmentos fundamental e médio nas redes públicas estadual e municipal no Estado do Rio de Janeiro. (1998-2011). No ensino superior, além de experiência na rede privada (2007-2013), atuou como professora orientadora on-line no projeto REDEFOR/UNICAMP (20112012) no curso de Especialização Lato Sensu para professores da Rede Pública de Ensino no Estado de São Paulo. E-mail: marileaatm@gmail.com.
} 
and politics, inspired by analyses by Achile Mbembe (2014), Beatriz Nascimento (2018); Frantz Fanon (2008), and Maria Aparecida da Silva Bento (2014).

Keywords: academic racism; affection; power relationships.

Não existe distância emocional quando a questão é raça

bell hooks

\section{$O$ acontecimento}

Em 2018, alguns meses após a defesa da minha tese, fui convidada para participar de evento em uma universidade cujo tema versava sobre espaço, alteridade e subjetivação. Dividiram a mesa comigo dois intelectuais brancos: uma mulher e um homem. Estávamos ali porque nossas pesquisas, de perspectivas diferenciadas, tinham algo a dizer sobre o tema. Com efeito, um gesto racista, ocorrido durante o evento e a forma como ele foi encaminhado, evidenciou que minha presença naquele evento não era natural.

Fui a primeira a falar, seguida do homem branco e, por fim, chegou a vez da mulher branca. Ela, nos minutos finais de sua fala, advertiu que pessoas de fora da periferia, especialmente pesquisadores e pesquisadoras, quando vão até lá precisam fazê-lo não por um dever moral, mas pelo prazer do encontro e dos aprendizados partilhados. Até aqui, eu mesma concordava com ela. Não há nada mais arrogante do que o movimento top-down com aqueles que supomos ser o Outro. Parece que no plano das ideias nós duas estávamos de acordo.

Contudo, minha concordância com a pesquisadora não duraria os próximos segundos. Na sequência, ela levantou-se de sua cadeira e, para ilustrar sua fala, tocou bruscamente no meu cabelo como se ele fosse um objeto qualquer, simulando o ato de colonizar. Você não leu errado! É isso mesmo! Sem pudor, sem nenhum aviso prévio, ela sentiu-se autorizada a usar o meu corpo para compor sua apresentação. A pesquisadora, que na ocasião usava uma muleta, não poupou esforços físicos para deslocar-se do 
seu lugar e realizar um gesto rude sobre meu cabelo. $\mathrm{O}$ ato foi tão surreal que na hora meu estômago embrulhou.

Mesmo confusa, por impulso, reagi dizendo: "Você acabou de fazer o que a academia branca costuma realizar com os pretos e pobres." Da plateia, majoritariamente branca, a única reação que pude ouvir foi de uma mulher negra. Todo o resto silenciou. A professora terminou sua apresentação oral como se nada tivesse acontecido. Nos momentos finais do evento, a organizadora tomou a palavra para realizar os agradecimentos e não fez nenhuma menção sobre ocorrido. Enquanto isso, como eu estava sentada entre os dois pesquisadores brancos que dividiram a mesa comigo, pude ouvir a mulher direcionar elogios ao trabalho do pesquisador, especialmente em relação à postura dele que, segundo ela, trata-se de uma prática não colonizadora quando em suas atividades acadêmicas dirige-se à periferia. Meu corpo acabara de ser alvo de um ataque e eles falavam como se eu não estivesse sentada entre eles e nada tivesse acontecido.

No tempo decorrido entre o ato racista e minha retirada daquele local, eu desejei que um buraco abrisse no chão para que eu pudesse desaparecer. A objetificação pública do meu corpo, acompanhada do pacto de silêncio generalizado, trouxe uma mescla de vergonha, raiva e, sobretudo, incredulidade de que aquilo havia acontecido comigo.

Eu não tenho dúvida de que grande parte das pessoas presentes naquele evento se autodefine como progressista, até mesmo antirracista, mas isso não foi suficiente para perturbar um pacto de silêncio. Nesse sentido, interrogo: o que permite que a intelectualidade branca, como aquelas pessoas que dividiram a mesa comigo, cujos trabalhos discutem múltiplas opressões, inclusive as raciais, sintam-se autorizadas a cometer um ato racista tão grosseiro e o gesto ser sustentado por um silêncio retumbante?

Para ser honesta, durante um tempo, eu também evitei responder essa questão porque todo evento traumático carrega um excesso insuportável. Meu desejo imediato era me livrar o mais rápido possível da lembrança. Talvez seja por isso que a náusea foi a primeira reação do meu corpo, uma tentativa de expelir o que me havia afetado. No entanto, o recalcado sempre retorna. Em 2019, durante os primeiros meses da pandemia, observando as fotos da defesa da minha tese, enquanto rememorava como aquele ritual havia sido um momento de celebrar a potência das mulheres negras, a lembrança do ato racista invadiu minha festa. O choro foi inevitável. A memória do trauma traía meu esforço de esquecer. Naquele momento, me dei conta que precisava enfrentar essa dor, senão ela me deixaria aprisionada 
na condição de objeto. Escrever é uma forma de produzir agenciamentos sobre o acontecimento. E teorizar, conforme bell hooks, é um gesto de autorrecuperação quando...

Nos opomos a essa violação, essa desumanização, quando buscamos autorrecuperação, quando trabalhamos para reunir os fragmentos do ser, para recuperar nossa história. Esse processo permite que nos vejamos como se fosse a primeira vez, pois nosso campo de visão não é mais configurado ou determinado somente pela condição de dominação. (hooks: 1984:302)

Tratando-se das violências racistas ocorridas nos meios acadêmicos, a necessidade de autorrecuperação tem favorecido que inúmeras intelectuais negras brasileiras, de diferentes gerações, como Beatriz Nascimento (2018b), Lélia Gonzalez (1984), Sueli Carneiro (2005), Janaína Damasceno Gomes (2008) e Viviane Angélica da Silva, (2015), para citar algumas, produzam conceitos e análises sobre como as opressões construídas sob as diferenças de raça, classe e gênero são vivenciadas nos meios acadêmicos, afetando os corpos negros e expressando-se de forma singular sobre as mulheres. Essas produções indicam que a formação acadêmica, ao abrir possibilidades de disputa de espaços e de narrativas com a branquitude, coloca as mulheres negras sob formas de violências silenciadas e até mesmo naturalizadas, porque tais gestos fazem parte da racionalidade institucional e os jogos de poder que atravessam as competições, as alianças e os interesses acadêmicos. Nesse trabalho, branquitude é concebida, conforme descreveram as pesquisadoras Maria Aparecida da Silva Bento (2002) e Lia Schucman (2014), como uma criação histórica e relacional cujos significados socialmente construídos conferem vantagens estruturais às pessoas brancas.

Inspirada por essas produções, defino racismo acadêmico como a maneira pela qual aspectos estruturais do racismo se expressam nos espaços acadêmicos, em especial nas universidades. Nesse sentido, o racismo acadêmico poder ser compreendido com uma tecnologia de poder cujas práticas de discriminação racial ocorrem de forma velada ou explícita. Esses atos fazem parte do funcionamento institucional que, no Brasil, historicamente se configurou como um espaço hegemonicamente branco e masculino. $\mathrm{O}$ racismo acadêmico materializa-se pelas escolhas epistemológicas, pela inexistência de um corpo discente e docente diverso em termos raciais e pela criação de entraves meritocráticos/burocráticos/financeiros que dificultam o acesso e/ou a permanência de pessoas não brancas, especialmente negras e indígenas, no espaço. 
Mas alguns dirão: puxa! a Universidade e o conhecimento estão sob ataques. Não seria hora de conciliação? Falar sobre racismo acadêmico não provocaria divisões? Sim, eu tenho consciência que o atual momento histórico impõe desafios políticos e teóricos singulares por conta do avanço do conservadorismo e da racionalidade neoliberal, expressos pelo ataque à justiça social e aos direitos humanos.

No entanto, as divisões já existem e não será possível descolonizar as práticas acadêmicas enquanto um dos lados da mesa silenciar as violências institucionais. Por conta disso, muitas pessoas do campo progressista alertam para a necessidade de descolonizar as epistemologias. Observo esse movimento descolonizador com entusiasmo e desconfiança. Entusiasmo, pelo fato de ser inadmissível que toda produção teórica do mundo continue sendo ditada por uma dúzia de homens brancos do Norte Global. Desconfiança, porque a distância entre o que se pesquisa o que se vive é uma prática corriqueira nos meios acadêmicos. Essa percepção tornou-se para mim mais aguda, após meu corpo ter sido alvo publicamente do racismo acadêmico, cujos agentes da ação são pessoas que em seus estudos articulam abordagens teóricas problematizadoras do racismo, do colonialismo e do sexismo. Em outras palavras, não basta apenas possuir um conhecimento bibliográfico sobre o racismo, é preciso uma dobra ética que implique transformações subjetivas radicais.

A escrita deste trabalho é um esforço para nos deslocarmos de uma abordagem sobre descolonização cuja aproximação com o tema fica restrita a um conhecimento intelectual e bibliográfico, ocorrendo poucas modificações no cotidiano das relações raciais vivenciadas nos espaços acadêmicos. Para tanto, considero fundamental a construção de pesquisas que enfrentem as conexões existentes entre afeto, racismo e relações de poder, expressas nas práticas de racismo acadêmico.

Antes de continuarmos nosso percurso, é importante situar que a concepção de afeto proposta neste trabalho alinha-se à abordagem do filósofo Baruch Spinoza (2013) que descreve o termo como as afecções do corpo, pelas quais sua potência de agir é aumentada ou diminuída, estimulada ou refreada, e, ao mesmo tempo, as ideias dessas afecções. Socialmente nomeamos sensações que atravessam os nossos corpos como amor, raiva, medo, mas vale dizer que os afetos não se confundem com o que chamamos de sentimentos. Os afetos são intensidades que atravessam os nossos corpos e muitas vezes não conseguimos nomear, mas que mobilizam nossos gestos, ações e pensamentos. 
Nos últimos anos, em termos teóricos, cada vez mais se reconhece nas Ciências Sociais a importância do afeto ao lado da razão, do cálculo e da estratégia nas múltiplas dinâmicas da vida, incluindo a política. Esse tem sido o fundamento teórico central do que atualmente denominamos virada afetiva. Nos Estados Unidos, desde a década de 1990, e no Brasil, nos últimos anos, a abordagem tem sido usada pelas teorizações feministas e queer.

Apesar das diferentes filiações teóricas em torno da virada afetiva, há, pelo menos, duas convergências que merecem destaque: primeiro, a rejeição de uma hierarquia entre mente e corpo para a construção do conhecimento. (Almeida: 2018); segundo, o enfoque tanto em nosso poder de afetar o mundo a nossa volta quanto o de sermos afetados por ele. (Hardt: 2015).

Angulada por essas abordagens pergunto: de que forma os afetos raciais exprimem o funcionamento das políticas acadêmicas, suas disputas e seus jogos de poder?

\section{Racismo, afeto e o pacto narcísico da branquitude}

Se por um lado atualmente a virada afetiva alcançou visibilidade, por outro é possível afirmar que intelectuais negras e negros que estudam as relações raciais vêm, de longa data, evidenciando como as dinâmicas afetivas e os códigos emocionais são incorporados nos processos de socialização racial, cujas expressões dessas afecções, por inúmeras vezes, validam a eliminação física ou subjetivamente de pessoas negras.

Na década de 1960, o psiquiatra Franz Fanon, em Pele Negra Máscaras Brancas, ao analisar os processos de racialização, denuncia um duplo narcisismo que emergiu desse processo: o branco confinado em sua brancura e na crença de sua superioridade; e o negro confinado em sua negrura e na ideia de sua inferioridade. (Fanon: 2008:27). A partir dessa crítica, Fanon detalha os afetos racistas mobilizados nos processos de socialização racial, descrevendo essas conexões por meio de suas experiências pessoais. "Eu acreditava estar construindo um eu fisiológico, equilibrando o espaço, localizando as sensações, e eis que exigiam de mim um suplemento". O suplemento é a sua negritude. Na rua, ele é apontado como um "preto". Uma criança branca diz: "Mamãe, olhe o preto, estou com medo". À medida que 
o cerco em torno da sua cor se fecha, Fanon descreve novas reações: "Quis gargalhar até sufocar, mas isso tornou-se impossível". (Fanon: 2008:105). Daí, a percepção de que seu corpo desperta um ódio racial difuso: "Era a raiva; eu era odiado, detestado, desprezado, não pelo meu vizinho da frente ou pelo primo materno, mas por toda uma raça, estava exposto a algo irracional". (Fanon: 2008:110).

Sobre esse algo irracional que mobiliza os afetos raciais, autores como Paul Gilroy e Achille Mbembe descrevem as intrínsecas relações entre racismo, racionalidade e afetos. Paul Gilroy (2012:17) definiu o racismo como "irracionalidades racionalizadas do pensamento racial e a aplicação racional do terror". Achille Mbembe (2014:11), narrando os processos de racialização do mundo na modernidade, afirma que, em "qualquer lugar onde apareça, o Negro liberta dinâmicas passionais e provoca exuberância irracional que tem abalado o próprio sistema racional". A palavra negro com $\mathrm{N}$ maiúsculo faz referência à racialização dos corpos negros e sua principal consequência: a naturalização de sua desumanização. Mbembe aproxima o racismo em termos de uma afecção, em que suas bases estão na própria construção da ideia de raça:

[...] raça é um lugar de realidade e de verdade - a verdade e das aparências. Mas é também um lugar de dilaceração, de efervescência e de fervor. A verdade do indivíduo a quem é atribuída uma raça está simultaneamente em outro lugar e nas aparências que lhes atribuídas. A raça está detrás da aparência e sob aquilo de que nos apercebemos. É também constituída pelo próprio ato de atribuição - esse meio pelo qual certas formas de infravida são produzidas e institucionalizadas, a indiferença e o abandono, justificando, a parte humana do Outro, violada, velada ou ocultada, e certas formas de enclausuramento, ou mesmo de condenação à morte, tornadas aceitáveis. (Mbembe: 2014:66)

Racismo, aquilo que cria as hierarquias raciais a partir da modernidade, é definido por Mbembe em termos de jogos de significação e dos efeitos de sentidos sobre os corpos, seja pela forma como percebemos, seja pelo modo como somos afetados por essa percepção. No que tange aos corpos racializados como negros, o que está em jogo é a aniquilação.

Deslocando-se para produção acadêmica brasileira, a historiadora Beatriz Nascimento, igualmente, descreveu a importância de prestarmos atenção nos circuitos afetivos quando estudamos as relações raciais. Em 1974, no artigo "Por uma história do homem negro", a historiadora questiona 
as implicações de uma abordagem historiográfica que narra as experiências negras pelo viés da escravização, ou seja, pela objetificação. Assim, questiona

Não se estuda, o negro que está vivendo, a História vivida. Somos a História Viva do Preto, não números. Devemos fazer nossa História, buscando nós mesmos, jogando nosso inconsciente, nossas frustrações, nossos complexos, estudando-os, não os enganando. (Nascimento:2018a:49)

Beatriz Nascimento, ciente da complexidade do racismo, advoga que não basta apenas investigações quantitativas, mas é preciso prestar atenção nas afecções que atravessam os processos de socialização racial. $\mathrm{Na}$ década de 1990, no texto "Por território (novo) existencial e físico", Beatriz Nascimento exemplifica como o incômodo com os rituais acadêmicos colonizadores favoreceu que ela permanece afastada durante dez anos do espaço. (Nascimento: 2018 a: p. 416). A narrativa da historiadora favorece a visualização do entrelaçamento entre a dimensão subjetiva das relações raciais com outras mais concretas e objetivas da vida, como, por exemplo, a própria permanência no espaço acadêmico.

A respeito dessas conexões, a psicóloga Maria Aparecida Silva Bento (2014), cuja pesquisa focaliza os processos de branqueamento nas instituições, sublinha que não se pode separar os aspectos subjetivos dos ganhos materiais, uma vez que ambos se reforçam mutuamente, funcionando como potencializadores do racismo. Essas conclusões são frutos de sua experiência no Centro de Estudos das Relações de Trabalho e Desigualdades - CEERT, ministrando cursos dirigidos ao movimento sindical e empresas privadas. Nessas ocasiões, a pesquisadora percebe que pessoas brancas progressistas que combatem a opressão e as desigualdades, com frequência, mantêm seu grupo protegido das avaliações e análises sobre o racismo. Cida Bento descreve que é comum ocorrer um sentimento de indignação com a violação dos direitos das trabalhadoras, mas só quando essa violação afeta o grupo de pertença. (Bento: 2014: p.26-29). Segundo a psicóloga, a autopreservação dos brancos, enquanto grupo privilegiado pelo racismo em termos simbólicos e materiais, ocorre por meio do pacto narcísico da braquitude, definido pela autora nos seguintes termos:

O silêncio, a omissão, a distorção do lugar do branco na situação das desigualdades raciais no Brasil têm um forte componente narcísico, de autopreservação, porque vem acompanhado de um pesado investimento na colocação desse grupo como grupo de referência da condição humana. (Bento: 2014: p. 30) 
Cida Bento faz uso da concepção de narcisismo em Freud para demonstrar como o amor a si mesmo, elemento psíquico que trabalha para a preservação do indivíduo, funciona no âmbito das relações raciais em uma sociedade racista. As práticas estudadas por Cida Bento explicitam a conexão entre afecções, pacto narcísico e a defesa dos interesses do grupo de pertença. Conforme descreve a psicóloga:

Ter a si próprio como modelo e projetar sobre o outro as mazelas que não se é capaz de assumir, pois maculam o modelo - são processos que, sob certos aspectos, podem ser tidos como absolutamente normais no desenvolvimento das pessoas. O primeiro está associado ao narcisismo e, o segundo, à projeção. No entanto, no contexto das relações raciais eles revelam uma faceta mais complexa porque visam justificar, legitimar a ideia de superioridade de um grupo sobre o outro e, consequentemente, as desigualdades, a apropriação indébita de bens concretos e simbólicos, e a manutenção de privilégios. (Bento:2014: p.31)

Notemos que o pacto narcísico da branquitude não pode ser dissociado dos privilégios simbólicos e materiais que uma pessoa branca desfruta em uma sociedade racista. Os circuitos afetivos mobilizados pelo racismo e suas implicações simbólicas e materiais descritos por esses trabalhos são sistematicamente silenciadas nas práticas do racismo acadêmico.

Uma vez realizado esse percurso teórico, podemos retomar algumas perguntas: o que permite que as práticas do racismo acadêmico sejam sustentadas por um silêncio retumbante? Como os circuitos afetivos e relações de poder estão imbricadas nesse silenciamento? De que forma o racismo acadêmico faz parte do funcionamento das instituições acadêmicas, em especial as universidades?

\section{Aprender a silenciar: o currículo oculto do racismo acadêmico}

Algumas semanas e meses depois do acontecimento racista que narrei no início do texto, me comuniquei com algumas pessoas brancas que estavam presentes durante o evento, algumas delas afirmaram que se sentiram profundamente incomodadas com o que havia ocorrido, inclusive com o 
fato delas mesmas terem silenciado. Essas pessoas expressaram um misto de vergonha e de decepção, já que algumas pessoas disseram que nutriam admiração pelo trabalho dos pesquisadores brancos que dividiam a mesa comigo. Uma dessas pessoas chegou a me dizer que amava a mulher que havia realizado o ato racista e, por isso, apesar de lamentar muitíssimo o que havia ocorrido não sabia o que dizer. Ela se sentia dividida e transtornada. Esses relatos apontam como as relações afetivas e o pacto narcísico estão imbricados, já que o amor a si mesmo, ou seja, o modelo branco, não podia ser maculado, porque abriria uma ferida narcísica insuportável de lidar.

Outra camada que podemos escavar sobre o silêncio diz respeito às relações de poder que atravessam as práticas institucionais. Muitas pessoas ficam desorientadas porque existe um cálculo que precisa ser feito: o/a professor/a de hoje pode transformar-se em orientador/a, depois integrante da banca de concurso ou avaliador/a de projetos e, por fim, em colega de departamento. A denúncia pode colocar em risco uma trajetória profissional. Em outras palavras, o modo como funciona a construção das carreiras acadêmicas favorece o silenciamento. Para usar uma frase muito comum: "ninguém quer ficar queimado". Assim, por meio de sua autopreservação, a branquitude do saber naturaliza sua hiper-representação nos espaços acadêmicos.

Ainda que muitas pessoas possam ficar indiferentes às práticas de racismo acadêmico, já que o mesmo é atávico ao próprio funcionamento institucional, essas falas me chamaram atenção para o fato de que o que sustenta o silêncio não é apenas a inexistência do incômodo. Mas a existência de um aprendizado de como manejar esse incômodo. Esse aprendizado funciona como uma espécie de currículo oculto. O sociólogo Michel Apple (1982), pesquisando o sistema escolar estadunidense, definiu currículo oculto como a dimensão implícita no processo educacional que não pode ser mensurável, porque faz parte do cotidiano quando se transmite experiências que reforçam aprendizados socioculturais dominantes e também como deve ser a interrelação entre professor, aluno e o conhecimento. Na visão de Michel Apple, o currículo oculto imprime no aluno disposições e propensões que poderão ser incorporadas em sua vida futura, especialmente tratando-se de uma sociedade cuja ordem social e econômica é estratificada. (Apple:1982). Valendo-se dessa abordagem sobre currículo oculto, podemos dizer que a naturalização do racismo acadêmico faz parte do aprendizado sobre o funcionamento institucional, o que implica o silenciamento dos incômodos e dos conflitos que possam surgir decorrentes das práticas racistas. 
Uma vez que o racismo acadêmico ocorre de forma sistêmica, ele afeta a autoconfiança das pessoas negras e brancas de maneiras diferentes. Enquanto as primeiras precisam lidar constantemente com sensação de inadequação e não pertencimento; as segundas têm sua autoconfiança reforçada por meio da representação hegemônica do seu grupo racial em termos físicos e epistemológicos. O silenciamento dos incômodos e dos pactos narcísicos se reforçam mutuamente, potencializando o racismo acadêmico e as vantagens simbólicas e materiais da branquitude.

Sem a observância ética da necessidade de articular de forma radical o que pensamos, dizemos e fazemos, os estudos descoloniais e o antirracismo serão facilmente capturados pela lógica da atualização acadêmica que, em última instância, está a serviço da carreira e da competição. E aqui não me refiro apenas às pessoas brancas, já que a intelectualidade negra não está imune a lógica do empresariamento de si, definido pelo psicanalista Aldo Ambrózio (2011) como o vínculo entre a racionalidade neoliberal e a produção de subjetividades como capitalistas de si mesmas. Nessa lógica, a intelectualidade branca, para demonstrar atualização acadêmica, pode aderir ao discurso descolonizador de forma superficial, e a intelectualidade negra pode ser transformada numa espécie de coaching antirracista.

Com efeito, descolonizar, conforme propõe bell hooks (2019), é um processo complexo que envolve ambos: o colonizador e o colonizado, que implica muitas vezes assumir a dor, reconhecer os medos e os desejos e, sobretudo, sair da lógica binária e maniqueísta do tipo nós somos bons, eles são maus. Para a intelectualidade branca, a tarefa exige análises sobre os seus processos de racialização, sondando como eles moldaram seus desejos, linguagem, cognição e afetos. É preciso ter coragem de assumir, sem subterfúgios, os privilégios, as implicações e as responsabilidades de ser uma pessoa branca em mundo racista. Para nós, pessoas negras, a tarefa é o de lutar contra a sedução do branqueamento acadêmico e o desejo de ser reconhecido nos termos de uma racionalidade colonizadora, violenta e competitiva. É preciso ficarmos atentas sobre as armadilhas de um discurso de representatividade negra vinculado a um modelo neoliberal. Muitas vezes sentimos vergonha e silenciamos porque isso fere nosso narcisismo, especialmente quando adotamos um posicionamento militante. E nos autopunirmos com questionamentos do tipo: como você permitiu que uma pessoa branca fizesse isso com você? Nessas ocasiões, chegamos a questionar a nossa própria conduta. Essa forma de pensar não respeita a nossa humanidade, justamente porque ela está fixada em termos 
identitários. Por mais que nos cuidemos, enquanto houver práticas racistas, nem sempre saberemos como agir e sentiremos dor. E silenciar não faz com que ela desapareça.

Nada disso é fácil porque o racismo é uma racionalidade que estrutura relações sociais, engendra práticas institucionais, cria forma de sujeitos e mobiliza afecções. A gente pode começar quebrando o silêncio por meio de uma fala que, além de denunciar o gesto racista, tenha coragem dizer da dor, expressão de nossa humanidade. Para isso, concluo evocando mais uma vez Frantz Fanon (2014: p: 25):

Não venho armado de verdades decisivas. Minha consciência não é dotada de fulgurâncias essenciais. Entretanto, com toda a serenidade, penso que é bom que certas coisas sejam ditas. Essas coisas, vou dizê-las, não gritálas. Pois, há muito tempo que o grito não faz mais parte de minha vida.

\section{Referências}

ALMEIDA, M. de. Território de afetos: práticas femininas antirracista nos quilombos contemporâneos do Rio de Janeiro. Tese (Doutorado em História Cultural) - Universidade Estadual de Campinas, Instituto de Filosofia e Ciências Humanas, Campinas, 2018.

ALMEIDA, S. O que é racismo estrutural? Belo Horizonte: Letramento, 2018 .

AMBRÓZIO, A. Empresariamento da vida: discurso gerencialista e processos de subjetivação. Tese (Doutorado em Psicologia Clínica da Pontifícia) - Universidade Católica de São Paulo, São Paulo, 2011.

APPLE, M. Ideologia e currículo. São Paulo, Brasiliense, 1982.

BENTO, M.A.S. "Branqueamento e branquitude no Brasil". In: CARONE, Iray; BENTO, Maria Aparecida Silva. (orgs). Psicologia Social do racismo: Estudos sobre branquitude e branqueamento no Brasil. Petrópolis: Editora Vozes, 2014. p. 25-57. 
CARNEIRO, S. A construção do outro como não ser como fundamental do ser. Tese (Doutorado em Educação) - Programa de Pós-Graduação em Educação - Universidade de São Paulo, 2005.

FANON, F. Pele Negra, máscaras brancas. Tradução: Renato Silveira. Salvador: EDUFBA, 2008.

GILROY. P. "Prefácio à edição brasileira". In: O Atlântico Negro. São Paulo: Editora 34; Rio de Janeiro: Universidade Candido Mendes, Centros de Estudos Afro-Asiáticos, 2012, p. 9-25.

GOMES, J. Elas são pretas: cotidiano de estudantes negras na Unicamp. Dissertação (Mestrado em Educação) - Faculdade de Educação, Universidade Estadual de Campinas, Campinas, 2008.

GONZALEZ, L. "Racismo e sexismo na cultura brasileira". In: Revista Ciências Sociais Hoje, Anpocs, 1984, p. 223-44.

hooks, bell. Erguer a voz: pensar como feminista, pensar como negra. Tradução de Cátia Bocaiuva Maringolo. São Paulo: Elefante, 2019a.

. Olhares negros: raça e representação. Tradução de Stephanie Borges. São Paulo: Elefante, 2019b.

. Ensinando pensamento crítico: sabedoria prática. Tradução: Bhuvi Libanio. São Paulo: Elefante, 2020,

HARDT, M. "Para que servem os afetos?" Intersemiose - revista digital, Recife, ano IV, n. 7, p. 9-14, jan./jun. 2015.

NASCIMENTO, M. B. "Por uma história do homem negro." In: Beatriz do Nascimento, Quilombola e intelectual: Possibilidades nos dias de destruição. Editora Filhos da África, 2018a, p. 42-49.

. "Por um território (novo) existencial e físico" In: Beatriz do Nascimento: Quilombola e intelectual. Possibilidades nos dias da destruição. Diáspora Africana: Editora Filhos da África, 2018. Coletânea organizada e editada pela União dos Coletivos Pan-Africanistas, 2018b, p. 413-30.

MBEMBE, A. "Introdução: O devir-negro do mundo". In: Crítica da Razão Negra. Lisboa: Antígona, 2014, p. 11.

SCHUCMAN, L. V. Entre o encardido, o branco e o branquíssimo: branquitude, hierarquia e poder na cidade de São Paulo: São Paulo: Annablume,2014. 
SILVA, V. A. Cores da tradição: uma história do debate racial na Universidade de São Paulo (USP) e a configuração racial do corpo docente. Tese (Doutorado em Educação) - Programa de Pós-Graduação em Educação, Universidade de São Paulo, São Paulo, 2015.

SPINOZA, B. A origem e a natureza dos afetos. In: Ética. Belo Horizonte: Autêntica Editora, 2013, p. 156- 259.

RECEBIDO EM: 29/03/2021

APROVADO EM: 05/04/2021 